DAMACENA, Fernanda Dalla Libera; SILVA, Renato Carvalho da. Bioinvasão por água de lastro: um problema de direito e uma ameaça à sustentabilidade. Revista Eletrônica Direito e Política, Programa de Pós-Graduação Stricto Sensu em Ciência Jurídica da UNIVALI, Itajaí, v.10, n.1, edição especial de 2015. Disponível em: www.univali.br/direitoepolitica - ISSN 1980-7791.

\title{
BIOINVASÃo POR ÁGUA DE LASTRO: UM PROBLEMA DE DIREITO E UMA AMEAÇA À SUSTENTABILIDADE
}

\author{
BIOINVASION BY BALLAST WATER: A PROBLEM OF LAW AND A THREAT \\ TO SUSTAINABILITY
}

\author{
Fernanda Dalla Libera Damacena ${ }^{1}$ \\ Renato Carvalho da Silva²
}

\begin{abstract}
SUMÁRIO: Introdução; 1. Zona Costeira Brasileira: caracterização e tutela jurídica; 2. Aspectos informativos sobre a água de lastro e o cenário em âmbito nacional; 3. Poder de polícia, deveres de prevenção e repressão previstos pela normatização nacional e internacional; 4. A judicialização da bioinvasão por água de lastro no Brasil e a incerteza científica; Considerações finais; Referências das fontes citadas.
\end{abstract}

RESUMO: A bioinvasão é um dos graves problemas ambientais da atualidade. Essa espécie de poluição tem origem em diversas vias de dispersão. O presente artigo optou pela água de lastro. Tendo a zona costeira brasileira como pano de fundo, e a bioinvasao via água de lastro como recorte descritivo, o artigo debruçou-se sobre o papel do Direito diante dos riscos e danos ambientais oriundos dessa espécie de contaminação. Para tanto, realizou-se revisão da literatura sobre a bioinvasão por água de lastro e sua tutela pelo Direito. Para responder ao problema de pesquisa os seguintes objetivos específicos foram perseguidos: abordou-se a caracterização da tutela jurídica da zona costeira brasileira; apresentaram-se os principais aspectos informativos sobre a água de lastro; discorreu-se sobre a competência fiscalizatória, deveres de prevenção e repressão impostos pelas legislações nacionais e internacionais; e, por fim, através da análise de decisões judiciais envolvendo a temática, discorreu-se acerca da judicialização da bioinvasão por água de lastro no Brasil, tópico absolutamente vinculado à incerteza científica, problemática que circunda a matéria. A título de considerações finais o estudo identificou as seguintes lacunas no trato da questão: grande fragilidade na fiscalização ambiental; poucas

\footnotetext{
${ }^{1}$ Mestre em Direito, Universidade do Vale do Rio dos Sinos. Especialista em Direito Público UFRGS. Professora da Graduação e Especialização em Direito Ambiental da UNISINOS. Advogada. Email:fdamacena@unisinos.br.

2 Bacharel em Ciências Jurídicas e Sociais - Universidade do Vale do Rio dos Sinos. E-mail: nato19761@hotmail.com.
} 
DAMACENA, Fernanda Dalla Libera; SILVA, Renato Carvalho da. Bioinvasão por água de lastro: um problema de direito e uma ameaça à sustentabilidade. Revista Eletrônica Direito e Política, Programa de Pós-Graduação Stricto Sensu em Ciência Jurídica da UNIVALI, Itajaí, v.10, n.1, edição especial de 2015. Disponível em: www.univali.br/direitoepolitica - ISSN 1980-7791.

decisões judiciais definitivas sobre o tema e, sobretudo, insuficiência de conhecimento técnico-científico sobre a matéria, ponto que pode ser claramente observado nas decisões judiciais já prolatadas.

Palavras-chave: Zona Costeira; Água de Lastro; Bioinvasão; Degradação Ambiental; Sustentabilidade.

ABSTRACT: The bioinvasion is one of the most serious environmental concerns today. This kind of pollution is emitted from various routes of dispersal. This article has opted for one of them, the ballast water. With the Brazilian coastal zone as a backdrop, and the bioinvasion by ballast water as a descriptive clipping, the article has focused on the role of the law in the face of environmental risks and damage from this kind of environmental contamination. The article has the following specific objectives: characterization of the legal protection of the Brazilian coastal zone; present the main informational aspects of ballast water; discuss the competence on surveillance, prevention and prosecution duties imposed by national and international law; and, finally, through the analysis of court decisions involving the issue, discuss about the legalization of bioinvasion by ballast water in Brazil, topic absolutely linked to scientific uncertainty. The study identified the following gaps in regards to the question: great weakness in environmental monitoring; very few court decisions on the subject and, above all, lack of technical and scientific knowledge, which is reflected in judicial decisions already handed down.

Keywords: Coastal Zone; Ballast Water; Bioinvasion; Environmental Degradation; Sustainability.

\section{INTRODUÇÃO}

Em uma sociedade marcada por infindáveis possibilidades de riscos oriundos da globalização e do avanço tecnológico, a efetivação do mandamento constitucional de manutenção de um ambiente ecologicamente equilibrado está cada vez mais ameaçada. Uma das características da sociedade atual é a incerteza e o desconhecimento científico em relação a alguns riscos ambientais.

A bioinvasão por água de lastro é um dos graves problemas ambientais da atualidade. Sua perpetuação pode comprometer a sustentabilidade dos ecossistemas, o que reflete na qualidade de vida das presentes e futuras gerações. Trata-se de um problema de direito a ser gerido sob forte influência 
DAMACENA, Fernanda Dalla Libera; SILVA, Renato Carvalho da. Bioinvasão por água de lastro: um problema de direito e uma ameaça à sustentabilidade. Revista Eletrônica Direito e Política, Programa de Pós-Graduação Stricto Sensu em Ciência Jurídica da UNIVALI, Itajaí, v.10, n.1, edição especial de 2015. Disponível em: www.univali.br/direitoepolitica - ISSN 1980-7791.

economica, política e, sobretudo, em um contexto de incerteza científica, o que torna a questão ainda mais complexa.

O lastro é um procedimento importante para a segurança da navegação, mas carrega um grande potencial de degradação ambiental. O tanque de um navio pode transportar substâncias e micro-organismos causadores de desequilíbrio ecológico e prejudiciais à saúde.

Assim como em outros países, a contaminação pela bioinvasão é uma realidade no Brasil. Desse modo, tendo a zona costeira brasileira como pano de fundo, e a bioinvasão por água de lastro como recorte descritivo, o artigo debruçou-se sobre o seguinte problema: qual o papel do Direito diante dos riscos ambientais oriundos dessa espécie de contaminação?

Para responder ao problema de pesquisa realizou-se uma revisão da literatura sobre a bioinvasão por água de lastro e sua tutela pelo Direito. A pesquisa partiu do fenômeno bioinvasão por água de lastro em território brasileiro e, na sequência, o analisou sob as perspectivas teórica, legislativa e jurisprudencial.

O estudo foi estruturado a partir de 4 (quatro) objetivos específicos. Inicialmente caracterizou-se a tutela jurídica da zona costeira brasileira. $\mathrm{Na}$ sequência, tendo em vista se tratar de linguagem pouco afeita à seara jurídica, alguns aspectos informativos sobre a água de lastro foram pontuados. Em um terceiro momento, discorreu-se sobre a competência fiscalizatória, deveres de prevenção e repressão impostos às autoridades competentes pela legislação nacional e internacional, bem como as possíveis responsabilidades decorrentes do descumprimento desses deveres. Por fim, através da análise de decisões judiciais envolvendo a temática, discorreu-se acerca da judicialização da bioinvasão por água de lastro no Brasil e o problema da incerteza científica que circunda a matéria.

Nesse contexto, duas questões são latentes diante do que pode ser considerado um dos mais graves problemas ambientais da atualidade: a fragilidade na fiscalização do principal foco de dispersão da poluição que são as embarcações e, sobretudo, a insuficiência de conhecimento técnico-científico sobre inúmeras 
DAMACENA, Fernanda Dalla Libera; SILVA, Renato Carvalho da. Bioinvasão por água de lastro: um problema de direito e uma ameaça à sustentabilidade. Revista Eletrônica Direito e Política, Programa de Pós-Graduação Stricto Sensu em Ciência Jurídica da UNIVALI, Itajaí, v.10, n.1, edição especial de 2015. Disponível em: www.univali.br/direitoepolitica - ISSN 1980-7791.

espécies invasoras específicas, bem como a forma ambientalmente correta de sua erradicação. O incentivo ao avanço da ciência, com metas e parâmetros de atuação definidos de acordo com o caso concreto, e as medidas de prevenção e precaução aparecem como critérios de decisão de grande relevância para a busca de solução do problema ambiental e, consequentemente, para a imposição de responsabilidades.

\section{ZONA COSTEIRA BRASILEIRA: CARACTERIZAÇÃO E TUTELA JURÍDICA}

A zona costeira brasileira é uma região de grande extensão, caracterizando-se como um dos ambientes mais vulneráveis do ecossistema mundial em virtude de serem "espaços geográficos de interação entre continentes, atmosfera e oceano, havendo assim, a integração de diversos sistemas ecológicos compostos por uma fauna e uma flora complexa e sensível". ${ }^{3}$

Outrossim, possui caracteristicas peculiares por sua importância turística, objeto de frequentes especulações imobiliárias, influenciando nos hábitos e modo de vida da região, os quais, na maior parte das vezes são explorados sem a devida preocupação ambiental, tanto por parte da população, quanto do Poder Público. ${ }^{4}$

O Brasil possui uma Zona Costeira equivalente a uma área de $8.694 \mathrm{~km}$, composta por uma grande variedade de ecossistemas como, manguezais, mariscais, estuários, dunas, falésias, costões rochosos, recifes de arenito, campos de dunas, baias, etc. ${ }^{5}$ Possui, também, uma acentuada produtividade

\footnotetext{
3 CARVALHO, Delton Winter de. A zona costeira brasileira e o gerenciamento dos danos ambientais futuros. Direito e ambiente. Portugal: Lusíada, 2011. p. 4. Disponível em: <http://www.icjp.pt/sites/default/files/media/895-1638.pdf>. Acesso em: 24 mai. 2013.

${ }^{4}$ FREITAS, Mariana Almeida Passos de. Zona costeira e meio ambiente. Curitiba: Juruá, 2011. p. 17.

5 CARVALHO, Delton Winter de. A zona costeira brasileira e o gerenciamento dos danos ambientais futuros. Direito e ambiente. Portugal: Lusíada, 2011. p. 5. Disponível em <http://www.icjp.pt/sites/default/files/media/895-1638.pdf>. Acesso em: 24 mai. 2013.
} 
DAMACENA, Fernanda Dalla Libera; SILVA, Renato Carvalho da. Bioinvasão por água de lastro: um problema de direito e uma ameaça à sustentabilidade. Revista Eletrônica Direito e Política, Programa de Pós-Graduação Stricto Sensu em Ciência Jurídica da UNIVALI, Itajaí, v.10, n.1, edição especial de 2015. Disponível em: www.univali.br/direitoepolitica - ISSN 1980-7791.

orgânica que dá origem a importantes cadeias alimentares de origem animal e vegetal. ${ }^{6}$

Nesse sentido, a Zona Costeira deve ser compreendida como microbem constituinte e componente do meio ambiente ecologicamente equilibrado (macrobem), para melhor gerenciamento dos riscos ambientais presentes e futuros oriundos das atividades desenvolvidas em seu âmbito. Por essas razão, sua utilização far-se-á, na forma da lei, dentro de condições que assegurem a sua preservação. Nessa linha, o termo patrimônio nacional que deve ser entendido em sentido amplo, como riqueza pertencente à coletividade em razão de sua condição de bem de uso comum do povo e, consequentemente, da sua indisponibilidade. A Zona Costeira consiste num bem de interesse público. ${ }^{7}$

Ao longo dos últimas décadas, esse patrimônio vem sendo afetado por diversas formas de degradação ambiental. Uma das mais nocivas é a introdução de espécies exóticas (bioinvasão). Um dos grande vetores de introdução dessas espécies é a água de lastro, utilizada na indústria naval.

\section{ASPECTOS INFORMATIVOS SOBRE A ÁGUA DE LASTRO E O CENÁRIO EM ÂMBITO NACIONAL}

Quando um navio está descarregado ou apenas com parte de sua capacidade, seus tanques são preenchidos com água para manter sua estabilidade, balanço e integridade estrutural. ${ }^{8}$ Esse procedimento recebe o nome de água de lastro.

6 BRASIL. Ministério do Meio Ambiente. Limites da zona costeira. Disponível em: <http://www.mma.gov.br/gestao-territorial/gerenciamento-costeiro/a-zona-costeira-e-seus$\mathrm{m} \% \mathrm{C} 3 \%$ BAltiplos-usos/caracteristicas-da-zona-costeira>. Acesso em: 24 mai. 2013. 0 artigo 20, § único, da Lei 7.661, de 1988, institui o plano de gerenciamento costeiro brasileiro e define a zona costeira.

7 CARVALHO, Delton Winter de. A zona costeira brasileira e o gerenciamento dos danos ambientais futuros. Direito e ambiente. Portugal: Lusíada, 2011. p. 10. Disponível em <http://www.icjp.pt/sites/default/files/media/895-1638.pdf>. Acesso em: 24 mai. 2013.

8 ZANELLA, Tiago Vinicius. Água de Lastro: Um problema ambiental global. Curitiba: Juruá, 2010. p. 18 . 
DAMACENA, Fernanda Dalla Libera; SILVA, Renato Carvalho da. Bioinvasão por água de lastro: um problema de direito e uma ameaça à sustentabilidade. Revista Eletrônica Direito e Política, Programa de Pós-Graduação Stricto Sensu em Ciência Jurídica da UNIVALI, Itajaí, v.10, n.1, edição especial de 2015. Disponível em: www.univali.br/direitoepolitica - ISSN 1980-7791.

$\mathrm{Na}$ indústria naval, o lastro tem como finalidade a estabilização das embarcações melhorando as condições de flutuabilidade e de manobrabilidade da embarcação. ${ }^{9}$ Sua definição está prevista na NORMAM no 20, da Diretoria de Portos e Costas. ${ }^{10}$

Geralmente a água utilizada como lastro é captada nas baías, estuários e oceanos, destinada a facilitar a tarefa de carga e descarga. Porém, juntamente com a água são captados todos os tipos de organismos presentes no local. É exatamente neste ponto que inicia os problemas causados pela bioinvasão.

Hoje a técnica do lastro é utilizada em todos os navios de carga de grande porte do Mundo. Considera-se que essas embarcações respondam por $80 \%$ do transporte de mercadorias mundiais. No Brasil esse índice aumenta ainda mais, correspondendo a $98 \%$ do transporte do comércio de importação e exportação. Estima-se que aproximadamente 10 bilhões de toneladas de água são transferidas anualmente como lastro, e cerca de 3.000 espécies de animais e plantas sejam transportados por dia em todo mundo". ${ }^{11}$

Tendo esses dados como ponto de partida, e tendo em consideração que o Planeta Terra é coberto por cerca de $70 \%$ de mares e oceanos, tem-se a real dimensão do significado do transporte marítimo para o desenvolvimento mundial, e como ele interfere de maneira definitiva no meio ambiente ecologicamente equilibrado. Ademais, a bacia hidrográfica, a zona Costeira e estuários são considerados ecossistemas e unidades espaciais para gestão da

\footnotetext{
9 FERREIRA, Carlos Eduardo L. GONÇALVES, José Eduardo A. COUTINHO, Ricardo. Cascos de Navios e Plataformas como vetores na Introdução de Espécies Exóticas. In: SILVA, Julieta Salles Vianna da. SOUZA, Rosa Cristina Correa Luz de (Org.). Água de lastro e bioinvasão. Rio de Janeiro: Interciência, 2004. p. 143-156.

10 BRASIL. Departamento de Portos e Costas - DPC. Normam 20, de 14 de junho de 2005. Gerenciamento da Água de Lastro de Navios. Disponível em: <https://www.dpc.mar.mil.br/Normam/N_20/Introducao.pdf>. Acesso em: 24 jul. 2013. É a água com suas partículas suspensas levada a bordo de um navio nos seus tanques de lastro, para o controle do trim, banda, calado, estabilidade ou tensões do navio, tendo em vista que todo navio é projetado para transitar carregado, além de ser economicamente muito mais viável.
}

11 ZANELLA, Tiago Vinicius. Água de Lastro: Um problema ambiental global. Curitiba: Juruá, 2010. p. 19. 
DAMACENA, Fernanda Dalla Libera; SILVA, Renato Carvalho da. Bioinvasão por água de lastro: um problema de direito e uma ameaça à sustentabilidade. Revista Eletrônica Direito e Política, Programa de Pós-Graduação Stricto Sensu em Ciência Jurídica da UNIVALI, Itajaí, v.10, n.1, edição especial de 2015. Disponível em: www.univali.br/direitoepolitica - ISSN 1980-7791.

água, com uma característica pontual: desconhecem fronteiras geopolíticas (territoriais). ${ }^{12}$

No Brasil, a Diretoria de Portos e Costas (DPC) estima que uma média anual de 40 milhões de toneladas de água de lastro são despejadas por navios comerciais em visita aos portos nacionais. Diante disso, ao longo dos últimos anos diversas espécies exóticas foram registradas nos portos brasileiros, introduzidas em áreas que recebem grande fluxo de navios. ${ }^{13}$

Até pouco tempo não havia interesse e, por consequência, pouca divulgação dos problemas ambientais associados á água de lastro ${ }^{14}$. A situação mudou no momento em que, através desta via de contaminação, ocorreu a invasão do mexilhão dourado, o que chamou a atenção das autoridades e da comunidade científica. Seu primeiro registro no Brasil deu-se no Rio Grande do Sul, em 1999. Hoje a espécie já é encontrada, em grande quantidade, em vários rios do estado. ${ }^{15}$

A falta de interesse pelo problema pode estar ligada à falta de informação sobre á espécie, o que contribuiu sobremaneira para tornar a bioinvasão por água de

12 CAMARGO, Eldis. A integração da gestão das bacias hidrográficas com a dos sistemas estuarinos e zonas costeiras. In: GRANZIELRA, Maria L. M; GONÇALVES Alcindo (orgs). Os problemas da Zona costeira no Brasil e no mundo.Santos: Leopoldianum, 2012, p.46.

13 STRESSER, Rafaela de Carvalho. Água de lastro: desastre ambiental. In: CONGRESSO INTERNACIONAL DE DIREITO AMBIENTAL, v.3, 2007, São Paulo. Meio ambiente e acesso à justiça: flora, reserva legal e app. São Paulo: Imprensa Oficial do Estado de São Paulo, 2007. p. 750.

14 "Em Itaipu, o mexilhão dourado alterou a rotina de manutenção das turbinas ao fazer reduzir o intervalo entre as paralisações, antecipando custos de quase US\$ 1 milhão a cada dia de paralisação do sistema. O mexilhão também se incrusta em estruturas portuárias, força mudanças nas práticas de pesca de populações tradicionais e prejudica o sistema de refrigeração de pequenas embarcações, não raro, fundindo motores. No Lago do Guaíba, o molusco mudou a rotina dos pescadores. A espécie rasga as redes, entope os aparelhos e causa prejuízos. No Pantanal Matogrossense, o mexilhão dourado tem sido encontrado na barriga de peixes". COLLYER, Wesley. Água de lastro, bioinvasão e resposta internacional. Revista Jurídica, Brasília, DF, v. 9, n. 84, abr./maio, 2007. Disponível em: <http://www.planalto.gov.br/ccivil_03/revista/Rev_84/artigos/WesleyCollyer_rev84.htm>. Acesso em: 24 mai. 2013.

15 AMBIENTEBRASIL. Justiça dá prazo para Ibama e governo gaúcho iniciarem combate a mexilhão invasor. Ambiente Brasil, São Paulo, 2006. Disponível em: <http://www.ambientebrasil.com.br/noticias/index>. Acesso em: 20 nov. 2013. O mexilhão dourado (Limnoperna fortunei) é um molusco de água doce e salobra de cerca de três centímetros de comprimento, originário dos rios asiáticos, principalmente da China. Na América do Sul, foi avistado pela primeira vez na desembocadura do Rio da Prata, na Argentina, em 1991, tendo lá chegado, certamente, através da água de lastro. Daí avançou pelos rios Paraná e Paraguai e alcançou o Pantanal. 
DAMACENA, Fernanda Dalla Libera; SILVA, Renato Carvalho da. Bioinvasão por água de lastro: um problema de direito e uma ameaça à sustentabilidade. Revista Eletrônica Direito e Política, Programa de Pós-Graduação Stricto Sensu em Ciência Jurídica da UNIVALI, Itajaí, v.10, n.1, edição especial de 2015. Disponível em: www.univali.br/direitoepolitica - ISSN 1980-7791.

lastro um risco ambiental catastrófico. ${ }^{16}$ Com efeito, a informação é um dos princípios básicos do direito ambiental e, sobretudo, do direito dos desastres. A extrema importância deste princípio decorre de sua origem, que remonta as fundações de legitimação democrática do Estado de Direito.

Diante dessa realidade, o Ministério do Meio Ambiente, mediante Portaria 494/2003, criou a Força Tarefa Nacional (FTN) para Controle do Mexilhão Dourado. A força tarefa foi composta por órgãos públicos federais (IBAMA, Ministérios, ANVISA, Polícia Rodoviária Federal, entre outros), secretarias estaduais do meio ambiente de alguns dos estados afetados e empresas geradoras de energia elétrica. Atuando sob a coordenação do IBAMA, a Força Tarefa Nacional está subdividida em quatro componentes: Divulgação ${ }^{17}$, Capacitação' Monitoramento e Fiscalização ${ }^{18}$. Sua finalidade é atuar sobre os vetores de dispersão do referido molusco, mexilhão dourado, para prevenção e controle de sua infestação em solo nacional. ${ }^{19}$

${ }^{16}$ CARVALHO, Délton Winter de. DAMACENA, Fernanda Dalla Libera. Direito dos desastres. Porto Alegre: Livraria do advogado, 2013. p. 43-44.

17 VERMULM JUNIOR, Harry. GIAMAS, Maria Teresa Duarte. Ocorrência do mexilhão dourado Limnoperna fortunei (Dunker, 1857) (Mollusca; Bivalvia; Mytilidae), no trato digestivo do "Armal" Pterodoras granulosus (Valenciennes, 1821) (Siluriformes; Doradidae), do rio Paraná, São Paulo, Brasil. Boletim Instituto de Pesca: São Paulo, v. 34, n. 1, p.175 - 179, 2008. Disponível em: <ftp://ftp.sp.gov.br/ftppesca/34_1_175-179.pdf>. Acesso em: 24 mai. 2013.

18 VERMULM JUNIOR, Harry. GIAMAS, Maria Teresa Duarte. Ocorrência do mexilhão dourado Limnoperna fortunei (Dunker, 1857) (Mollusca; Bivalvia; Mytilidae), no trato digestivo do "Armal" Pterodoras granulosus (Valenciennes, 1821) (Siluriformes; Doradidae), do rio Paraná, São Paulo, Brasil. Boletim Instituto de Pesca: São Paulo, v. 34, n. 1, p.175 - 179, 2008. Disponível em: <ftp://ftp.sp.gov.br/ftppesca/34_1_175-179.pdf>. Acesso em: 24 mai. 2013.

19 VERMULM JUNIOR, Harry. GIAMAS, Maria Teresa Duarte. Ocorrência do mexilhão dourado Limnoperna fortunei (Dunker, 1857) (Mollusca; Bivalvia; Mytilidae), no trato digestivo do "Armal" Pterodoras granulosus (Valenciennes, 1821) (Siluriformes; Doradidae), do rio Paraná, São Paulo, Brasil. Boletim Instituto de Pesca: São Paulo, v. 34, n. 1, p.175 - 179, 2008. Disponível em: <ftp://ftp.sp.gov.br/ftppesca/34_1_175-179.pdf>. Acesso em: 24 mai. 2013. Recentemente, outro caso de espécie invasora colocou novamente em alerta a comunidade científica brasileira. Trata-se do siri Charybdis hellerii. ${ }^{19} \mathrm{O}$ siri Charybdis hellerii, originário dos oceanos Índico e Pacífico, chegou ao Brasil provavelmente na água de lastro colhida no Caribe. Hoje ele está presente na Baía de Todos os Santos (BA), e nas Baías de Sepetiba e Guanabara (RJ). Trata-se de um siri, sem valor comercial, que está substituindo as populações de caranguejos, o que vem causando prejuízos à comunidade de pescadores. 
DAMACENA, Fernanda Dalla Libera; SILVA, Renato Carvalho da. Bioinvasão por água de lastro: um problema de direito e uma ameaça à sustentabilidade. Revista Eletrônica Direito e Política, Programa de Pós-Graduação Stricto Sensu em Ciência Jurídica da UNIVALI, Itajaí, v.10, n.1, edição especial de 2015. Disponível em: www.univali.br/direitoepolitica - ISSN 1980-7791.

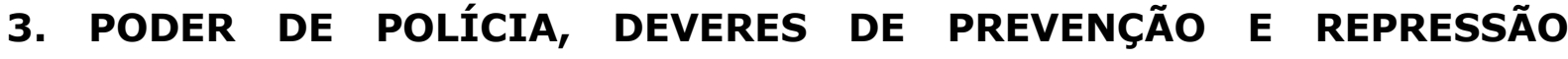 PREVISTOS PELA NORMATIZAÇÃO NACIONAL E INTERNACIONAL}

A fiscalização da poluição marítima em território nacional está a cargo da Marinha Brasileira, que recebeu essa atribuição da Lei Complementar n. 97/9920.

De acordo com a Lei n. 9.537/1997, que dispõe sobre a segurança do tráfego aquaviário em águas sob jurisdição nacional, "à autoridade marítima cabe assegurar a salvaguarda da vida humana e a segurança da navegação, no mar aberto e hidrovias interiores, e a prevenção da poluição ambiental por parte de embarcações, plataformas ou suas instalações de apoio". ${ }^{21} \mathrm{O}$ poder de polícia marítima se manifesta através de medidas preventivas e repressivas, havendo previsão legal de responsabilização por ação e omisssão ${ }^{22}$. No último caso, há a possibilidade de aplicação de multa e apreensão da embarcação.

Relevante destacar que de acordo com o artigo 23, VI, da Constituição Federal, "é competência comum da União, dos Estados, do Distrito Federal e Municípios proteger o meio ambiente e combater a poluição em qualquer de suas formas". Logo, a responsabilidade fiscalizatória, fundamental no caso da água de lastro, é de todos, indistintamente.

Os incisos III, VI e VII do caput e o parágrafo único do artigo 23 da Constituição Federal foram regulamentados pela Lei Complementar 140/2011. Um dos objetivo dessa lei, previsto no artigo 30, I, é a proteção, defesa e conservação do meio ambiente ecologicamente equilibrado, promovendo gestão descentralizada, democrática e eficiente. Dentre as ações administrativas comuns da União, Estados e Municípios está a promoção do desenvolvimento de estudos e

\footnotetext{
20 Art. 17, IV da LC 97/99 - Cabe à Marinha, como atribuições subsidiárias particulares: implementar e fiscalizar o cumprimento de leis e regulamentos, no mar e nas águas interiores, em coordenação com outros órgãos do Poder Executivo, federal ou estadual, quando se fizer necessária, em razão de competências específicas. Cabe à Marinha, como atribuições subsidiárias particulares:

${ }^{21}$ BRASIL. Lei 9.537, de 11 de dezembro de 1997. Dispõe sobre a segurança do tráfego aquáviario em águas sob jurisdição nacional e dá outras providências. Artigo 30 . Disponível em: <http://www.planalto.gov.br/ccivil_03/leis/19537.htm>. Acesso em: 24 mai. 2013.

22 SANTOS, Valdir Andrade. Poluição marinha: uma questão de competência. Aspectos da Lei 9.966 de 28/04/2000. Rio de Janeiro: Lumen Juris, 2010. p. 39.
} 
DAMACENA, Fernanda Dalla Libera; SILVA, Renato Carvalho da. Bioinvasão por água de lastro: um problema de direito e uma ameaça à sustentabilidade. Revista Eletrônica Direito e Política, Programa de Pós-Graduação Stricto Sensu em Ciência Jurídica da UNIVALI, Itajaí, v.10, n.1, edição especial de 2015. Disponível em: www.univali.br/direitoepolitica - ISSN 1980-7791.

pesquisas direcionados à proteção e à gestão ambiental. Dada a incerteza científica que circunda o problema das espécies invasoras, a precaução através do desenvolvimento do conhecimento é medida da mais alta relevância.

No que concerne especificamente ao problema da contaminação por espécies invasoras, nos termos do artigo 70, XVII, da referida lei, "o controle sobre a introdução no País de espécies exóticas potencialmente invasoras, que possam ameaçar os ecossistemas, habitats e espécies nativas, é ação administrativa atribuída à União".

Em uma situação a posteriori, quando as medidas preventivas falharam ou não foram empregadas, a hipótese de responsabilização por dano está prevista no artigo 70 da Lei 7.661/88, segundo a qual: "a degradação dos ecossistemas, do patrimônio e dos recursos naturais da Zona Costeira implicará ao agente a obrigação de reparar o dano causado e a sujeição às penalidades previstas no art. 14 da Lei no 6.938, de 31 de agosto de 1981". Entretanto, ainda que a legislação brasileira tenha optado pela responsabilização objetiva, um dos elementos para a imposição dessa responsabilidade é o nexo causal. E identificar que navio transportou determinada espécie invasora, de modo a desencadear um dano é o ponto nevrálgico da demanda. Note-se que apenas este ponto mereceria uma análise específica, entretanto, o objetivo deste artigo é destacar um problema ambiental transgeracional que não tem recebido a devida atenção dos agentes competentes, bem como chamar àtenção para o importante papel do direito nessse contexto ${ }^{23}$.

Embora não tenha regulamentação específica sancionatória no ordenamento jurídico brasileiro, o arcabouço legislativo exposado revela que as medidas de prevenção e repressão em relação à poluição por espécies invasoras são

\footnotetext{
${ }^{23}$ Talvez a única saída para a solução sejam as teorias de flexibilização do nexo causal, já apontadas como fundamento para a imputação de responsabilidades em casos como, por exemplo, a emissão dos gases que causam o efeito estufa. Para tanto ver: CARVALHO, Délton Winter de. ; LEITE, José Rubens Morato. O nexo de causalidade na responsabilidade civil por danos ambientais. Revista de Direito Ambiental, v. 47, p. 76-95, 2007.
} 
DAMACENA, Fernanda Dalla Libera; SILVA, Renato Carvalho da. Bioinvasão por água de lastro: um problema de direito e uma ameaça à sustentabilidade. Revista Eletrônica Direito e Política, Programa de Pós-Graduação Stricto Sensu em Ciência Jurídica da UNIVALI, Itajaí, v.10, n.1, edição especial de 2015. Disponível em: www.univali.br/direitoepolitica - ISSN 1980-7791.

plenamente aplicáveis, tanto à luz das normas de direito nacional quanto internacional. ${ }^{24}$

Embora os danos causados pelas espécies invasoras já sejam uma realidade, a prevenção, que se pratica através da fiscalização, continua a ser crucial, especialmente para evitar que novas espécies, além das já detectadas, adentrem o território brasileiro. Relevante destacar neste contexto, que a prevenção não é apenas um alternativa, mas uma imposição também da Convenção Internacional para Controle e Gerenciamento da Àgua de Lastro e Sedimentos de Navios. De acordo com o documento, as partes signatárias da (dentre os quais o Brasil), se comprometem a estimular o desenvolvimento contínuo do Gerenciamento de Água de Lastro e de normas para prevenir, minimizar e, por fim, eliminar a transferência de Organismos Aquáticos Nocivos e Agentes Patogênicos; através do controle e gerenciamento da Água de Lastro dos navios e dos sedimentos nela contidos.

A contaminação por água de lastro enquadra-se no conceito de poluição do meio marinho, definida pelo artigo 1 (4) da Convenção de Montego Bay (1982), ${ }^{25}$ que representa uma consolidação genérica das regras atinentes ao direito do mar. ${ }^{26}$ Além disso, é típico exemplo de poluição transfronteiriça que, nas palavras de Guido Soares, "supõe a ação do homem, ao introduzir elementos prejudiciais aos bens protegidos pelo direito internacional do meio ambiente como: a saúde humana, os recursos biológicos ou os sistemas ecológicos (ou seja a relação entre os seres vivos e o seu ecossistema)". ${ }^{27}$

\footnotetext{
24 HABER, Lilian Mendes. KOURY, Suzy Cavalcante. Gestão ambiental portuária: prevenção e repressão do risco ambiental decorrente da bioinvasão por água de lastro. In: Sustentabilidade: ensaio sobre direito ambiental. São Paulo: Método, 2010. p. 164.

25 É conceituada como a introdução pelo homem, direta ou indiretamente, de substâncias ou de energia no meio marinho, incluindo os estuários, sempre que a mesma provoque ou possa vir provocar efeitos nocivos, tais como danos aos recursos vivos e à vida marinha, riscos à saúde do homem, entrave às atividades marítimas, incluindo a pesca e as outras utilizações legítimas do mar, alteração da qualidade da água do mar, no que se refere à sua utilização, e deterioração dos locais de recreio.

26 MARTINS, Eliane M. Octaviano. Responsabilidade internacional e poluição marinha. Revista CEJ, v. 9, n. 29, p. 27-37, 2005.

27 SOARES, Guido Fernando Silva. Direito internacional do meio ambiente: emergências, obrigações e responsabilidades. São Paulo: Atlas, 2001, p.215.
} 
DAMACENA, Fernanda Dalla Libera; SILVA, Renato Carvalho da. Bioinvasão por água de lastro: um problema de direito e uma ameaça à sustentabilidade. Revista Eletrônica Direito e Política, Programa de Pós-Graduação Stricto Sensu em Ciência Jurídica da UNIVALI, Itajaí, v.10, n.1, edição especial de 2015. Disponível em: www.univali.br/direitoepolitica - ISSN 1980-7791.

A proteção contra apoluição transfronteiriça fundamenta-se nos princípios de interdição de abuso de direito, ou, ainda, no princípio da vizinhança internacional. Disso decorre a premissa de que um Estado não poderá sofrer danos por fatos ocorridos em outro. Assim, um Estado que causa poluição cujos efeitos extrapolem suas fonteiras deverá pelos danos decorrentes. ${ }^{28}$

\section{A JUdicialização dA BIOINVASÃo POR ÁGUA DE LASTRO NO BRASIL E A INCERTEZA CIENTÍFICA}

Ainda são poucas as ações e, por consequência, decisões judiciais envolvendo a poluição por água de lastro no judiciário Brasileiro. O artigo optou por analisar algumas ações que aglutinam problemas, discussões e medidas comuns referentes à matéria. ${ }^{29}$ As ações tratam da espécie invasora conhecida como mexilão dourado. A primeira possui julgamento de mérito, e a segunda encontrase suspensa em decorrência da realização de acordo judicial.

A ação Civil Pública no. 2006.71.00.021446-8/RS foi ajuizada em face do Estado do Rio Grande do Sul e do IBAMA, visando a execução de ações com o intuito de combater a proliferação desordenada do molusco. Para o órgão ministerial, embora a Secretaria Estadual do Meio Ambiente - SEMA e o IBAMA tivessem conhecimento do problema, ambos protelaram a solução, o que configuraria omissão enquanto a praga se prolifera, ensejando danos ambientais e econômicos ${ }^{30}$

\footnotetext{
${ }^{28}$ MARTINS, Eliane M. Octaviano. Responsabilidade internacional e poluição marinha. Revista CEJ, v. 9, n. 29, p. 27-37, 2005, p.28.

${ }^{29}$ Exemplo são as ACP (s) no. 2006.71.00.021446-8/RS e no. 0000764-05.2012.4.03.6124/SP.

30 BRASIL. Tribunal Regional Federal (4. Região; 9a Vara Federal de Porto Alegre). Sentença. Processo n. 2006.71.00.021446-8. Autor: Ministério Público Federal. Réus: Estado do Rio Grande do Sul e Instituto Brasileiro do Meio Ambiente e dos Recursos Naturais Renováveis IBAMA. Juíza Federal Substituta Clarides Rahmeier. Porto Alegre, 04 de novembro de 2013. Disponível

em: <http://www.trf4.gov.br/trf4/processos/visualizar_documento_gedpro.php?local=jfrs\&documento=

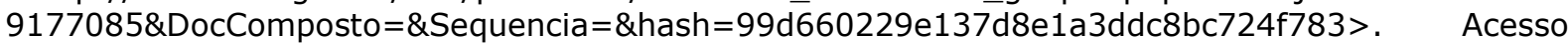
em: 15 mai. 2014.
} 
DAMACENA, Fernanda Dalla Libera; SILVA, Renato Carvalho da. Bioinvasão por água de lastro: um problema de direito e uma ameaça à sustentabilidade. Revista Eletrônica Direito e Política, Programa de Pós-Graduação Stricto Sensu em Ciência Jurídica da UNIVALI, Itajaí, v.10, n.1, edição especial de 2015. Disponível em: www.univali.br/direitoepolitica - ISSN 1980-7791.

Em sede de defesa, o Estado do Rio Grande do Sul e o IBAMA apresentaram alegações semelhantes, quais sejam: há três anos vêm trabalhando no estudo científico do mexilhão dourado, verificando suas áreas de incidência e possibilidades de invasão em outras áreas; mas a espécie aquática é de difícil acompanhamento, pois as larvas são microscópicas. Ademais, afirmam que a biologia desconhece a existência de qualquer método de controle ou erradicação ambientalmente viável. ${ }^{31}$

A ação foi proposta em 2006. Em 2013, a sentença reconheceu a situação como de extrema gravidade. Afinal, ao mesmo tempo em que o molusco se mostra altamente degradador, a ciência ainda não conseguiu encontrar um método adequado para erradicá-lo, sem causar sequelas ao meio ambiente. Contudo, de acordo com a decisão, "a ausência de método científico, não justifica a omissão dos órgãos competentes". A ação foi julgada parcialmente procedente, condenando os réus, conjuntamente, a uma série de obrigações de fazer ${ }^{32}$. As medidas revelam um verdadeiro plano de gestão com vistas à mitigação e à erradição da espécie invasora no Estado. Dentre elas, merece destaque a imposição que determina a fiscalização e implantação em todos os portos, instalações portuárias, terminais, plataformas e instalações de apoio, no Estado do Rio Grande do Sul, de um sistema ou instalação para recebimento e tratamento da água de lastro, dentro do prazo de 3 (três) anos.

31 BRASIL. Tribunal Regional Federal (4. Região; 9a Vara Federal de Porto Alegre). Sentença. Processo n. 2006.71.00.021446-8. Autor: Ministério Público Federal. Réus: Estado do Rio Grande do Sul e Instituto Brasileiro do Meio Ambiente e dos Recursos Naturais Renováveis IBAMA. Juíza Federal Substituta Clarides Rahmeier. Porto Alegre, 04 de novembro de 2013. Disponível em: <http://www.trf4.gov.br/trf4/processos/visualizar_documento_gedpro.php?local=jfrs\&documento=

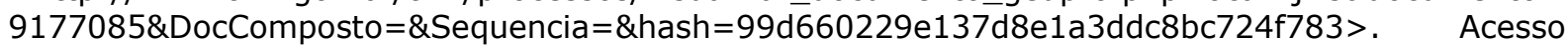
em: 15 mai. 2014.

32 Mapeamento das áreas de ocorrência do mexilhão; identificação das áreas mais suscetíveis à invasão e mitigação dessa vulnerabilidade; programa de informação e educação sobre as áreas já infestadas; estabeleciemnto de um método de inspeção nos cascos de embarcações (de pequeno, de médio ou de grande porte) e assemelhados nas rodovias e nos corpos hídricos; aprsentação de estudos de biologia e genética do mexilhão dourado, que indiquem a forma ecologicamente adequada para a total erradicação do molusco; cumprimento do disposto no art. 15 da Lei no 9.966/00 por todos os navios ou assemelhados, que estiverem em atividade de carga/descarga no Estado do Rio Grande do Sul; elaboração de estudos com tintas antiincrustantes visando analisar qual a mais adequada para utilização no caso concreto, e, ato contínuo, adotar todas as medidas necessárias à sua implantação. 
DAMACENA, Fernanda Dalla Libera; SILVA, Renato Carvalho da. Bioinvasão por água de lastro: um problema de direito e uma ameaça à sustentabilidade. Revista Eletrônica Direito e Política, Programa de Pós-Graduação Stricto Sensu em Ciência Jurídica da UNIVALI, Itajaí, v.10, n.1, edição especial de 2015. Disponível em: www.univali.br/direitoepolitica - ISSN 1980-7791.

Em caso semelhante, na Ação Civil Pública no. 0000764-05.2012.4.03.6124/SP, Ministério Público Federal postulou a condenação da Companhia Energética de São Paulo, a União, o IBAMA e o Estado de São Paulo, pelo descumprimento das determinações constitucionais do artigo 225 da Constituição, bem como da legislação ambiental. Requereu, ainda, a execução de ações com o intuito de combater a proliferação desordenada "mexilhão dourado", no Reservatório de Ilha Solteira, economicamente explorado pela CESP, para geração de energia elétrica, sob regime de concessão. ${ }^{33}$

Em meio a uma sucessão de recursos houve a designação e realização de uma audiência pública, oportunidade em que fora proposto e aceito, pelos presentes, um acordo judicial. $\mathrm{O}$ acordo estabeleceu a constituição, imediata, do grupo de trabalho, com composição, objetivos ${ }^{34}$, atribuições e prazos estabelecidos.

Os casos em comento exemplificam bem o quanto a solução do problema é desconhecida pela a ciência e de que forma esse desconhecimento reflete nas decisões judiciais. O número de ações sob análise do poder judiciário vem crescendo, mas ainda é pequeno. Por essa razão, uma conclusão definitiva sobre o posicionamento do poder judiciário brasileiro acerca da responsabilização pela bioinvasão por água de lastro seria prematura. De todo modo, não restam dúvidas de que essa espécie de poluição é um problema de direito.

Percebe-se que, contudo, que a bioinvasão por água de lastro revela um dos maiores desafios já imposto à política e ao direito ambiental, qual seja, a gestão

33 BRASIL. Tribunal Regional Federal. (3. Região). Agravo de Instrumento n. 001807344.2013.4.03.0000. Agravante: Cia Energética de Sao Paulo CESP. Agravado: Ministério Publico Federal. Relatora: Desembargadora Federal Consuelo Yoshida. São Paulo, 18 de dezembro de 2013. Disponível

em:

<http://www.trf3.jus.br/NXT/Gateway.dll?f=templates\&fn=default.htm\&vid=trf3e:trf3ve>. Acesso em: 15 mai. 2014.

${ }^{34}$ Referido Grupo de Trabalho, com repersentantes indicados, pelos réus, deverá elaborar relatório contendo um plano de ação, no qual serão avaliados, no mínimo, os seguintes itens: (A) métodos de monitoramento; (B) as medidas de controle do mexilhão adotadas pelos usuários do reservatório para verificação de sua eficácia; (C) proposta de programa para prevenção da dispersão do mexilhão; (D) proposta de programa para educação dos usuários da represa de Ilha Solteira (E) levantamento de grupos de pesquisa em Universidades, públicas e privadas, e Faculdades de Tecnologia, com o objetivo de fomentar pesquisas que subsidiem o controle da espécie. 
DAMACENA, Fernanda Dalla Libera; SILVA, Renato Carvalho da. Bioinvasão por água de lastro: um problema de direito e uma ameaça à sustentabilidade. Revista Eletrônica Direito e Política, Programa de Pós-Graduação Stricto Sensu em Ciência Jurídica da UNIVALI, Itajaí, v.10, n.1, edição especial de 2015. Disponível em: www.univali.br/direitoepolitica - ISSN 1980-7791.

das incertezas científicas. Nesses casos, a decisão acerca da hipótese de responsabilização passa pelo esclarecimento acerca de critérios científicos claros relacionados à hipótese de erradicação da espécie invasora. Ocorre que, não bastasse a ausência de estudos científicos esclarecedores, as técnicas conhecidas e disponíveis, atualmente, prejudicam o ambiente.

Em casos como esse a irrenunciável função decisória, uma das grandezas do direito, pode transformar-se em uma tarefa de grande complexidade, pois a decisão tende a ser tomada em um contexto de desconhecimento ou incerteza científica. ${ }^{35}$

Antecipando-se à realidade vicenciada pelo direito na atualidade, em "A lógica da investigação científica", Popper ${ }^{36}$ prenunciara que a ciência não oferece certezas, mas probabilidades, de modo que a probabilidade é hoje, a princípal referência operada pela atividade científica. O distanciamento dos pocisionamentos categóricos e terminativos tem sido a postura científica mais comum da ciência na atualidade.

Situações como a da bioinvasão por água de lastro desestabilizam e irritam um sitema como o Direito, estruturado sob as bases da segurança jurídica. No caso em específico dessa espécie invasora, observa-se que as decisões estão permeadas pela incerteza científica e demandam a necessidade de maiores estudos.

Diante dessa realidade, as convenções internacionais, das quais o Brasil é signatário, e a legislação pátria, têm sido os fundamentos das decisões que, por hora, têm determinado a realização de estudos e o emprego de métodos de prevenção à bioinvasão.

A aplicabilidade do princípio da precaução, sob o fundamento de que o desconhecimento científico não justifica a omissão por parte das autoridades

\footnotetext{
35 PARDO, José Esteve. El desconcierto del Leviatã : política y derecho ante las incertidumbres de la ciência. Buenos Aires: marcial Pons, 2009, p.21.

${ }^{36}$ POPPER, Karl R. A lógica da pesquisa científica. Tradução de Leonidas Hegenberg e Octanny da Motta. São Paulo: Cultrix, 1972.
} 
DAMACENA, Fernanda Dalla Libera; SILVA, Renato Carvalho da. Bioinvasão por água de lastro: um problema de direito e uma ameaça à sustentabilidade. Revista Eletrônica Direito e Política, Programa de Pós-Graduação Stricto Sensu em Ciência Jurídica da UNIVALI, Itajaí, v.10, n.1, edição especial de 2015. Disponível em: www.univali.br/direitoepolitica - ISSN 1980-7791.

competentes, é adequada. Nesse contexto, o desenvolvimento do conhecimento científico abre as portas para a elaboração de critérios que permitam a imposição de responsabiliades.

Enquanto se aguarda o avanço da ciência para a erradicação das expécies invasoras, as ações fiscalizatórias e mitigatórias crescem em importânica. Essa atuação somente será possível por um esforço conjunto do poder judiciário e órgãos administrativos competentes. Além disso, a hipótese de criação de um sistema para recebimento e tratamento da água de lastro aparece como importante medida de mitigação. Todavia, essa medida, imposta como obrigação de fazer ao Estado do Rio Grande do Sul, em decisão judicial, terá, ainda, que superar a deficiência da máquina pública no âmbito técnico e fiscalizatório.

A bioinvasão por água de lastro afeta os três pilares da sustentabilidade enumerado por Canotilho: ecológico, econômico e social. Ademais, em termos jurídico-políticos, o problema compromete, sobremaneira, duas das três dimensões básicas da sustentabilidade ilustradas pelo autor: a sustentabilidade geracional que aponta para a equidade entre diferentes grupos etários da mesma geração; e a sustentabilidade intergeracional, impositiva da equidade entre pessoas vivas no presente e pessoas que nascerão no futuro. ${ }^{37}$

No mundo contemporâneo, o Judiciário cada vez mais deixa de ser um poder de Estado, destinado apenas a decidir os conflitos que lhe são submetidos, para ser o farol da justiça ambiental e das atitudes condizentes com a proteção ecológica para as presentes e futuras gerações. Todavia, a redução da complexidade gerada pela bioivasão por água de lastro exige que o direito utilize-se de processos, procedimentos, programas para a assimilação do futuro e da gestão dos riscos.

37 CANOTILHO, José Joaquim Gomes. O Princípio da sustentabilidade como Princípio estruturante do Direito Constitucional. Tékhne-Revista de Estudos Politécnicos, n. 13, p. 07-18, 2010. Sobre a temática da sustentabilidade ver: FERRER, Gabriel. Sostenibilidad, transnacionalidad y transformaciones del derecho. Revista de Derecho Ambiental, outubre/deciembre, 2012, p.6583. 
DAMACENA, Fernanda Dalla Libera; SILVA, Renato Carvalho da. Bioinvasão por água de lastro: um problema de direito e uma ameaça à sustentabilidade. Revista Eletrônica Direito e Política, Programa de Pós-Graduação Stricto Sensu em Ciência Jurídica da UNIVALI, Itajaí, v.10, n.1, edição especial de 2015. Disponível em: www.univali.br/direitoepolitica - ISSN 1980-7791.

Complementarmente, a reflexão a repeito da teoria da complexidade de Fritjof Capra $^{38}$ parece bastante pertinente. Para o autor, a noção de rede é a ideia central da vida. $^{39}$ Tudo está interconectado e, por isso, todas as relações se comunicam. Capra se preocupa com a relação entre os seres humanos e a relação desses com o meio ambiente. Nesse sentido, o grande desafio do século XXI é promover a mudança de valores que determinam a economia global e chegar a um sistema compatível com adignidade humana e a sustentabilidade ecológica. Pela filosofia em comento, a consciência do todo é o grande auxílio para que o juíz eleja os melhores princípios para o caso, assim, e encontre a melhor solução. ${ }^{40}$

A bioinvasão por água de lastro deve ser tratada com o devido cuidado e deferência também pelos demais poderes. Afinal, como oportunamente discorreu Dworkin"1: "se o governo não leva os direitos a sério, então tampouco leva a sério o direito".

\section{CONSIDERAÇÕES FINAIS}

Durante toda a história da navegação marítima houve a incrustação de organismos nos cascos dos navios, sendo essa, portanto, a responsável pelas invasões de espécies não nativas em ambientes marinhos diversos. Contudo, nos dias atuais, a descarga de água de lastro é a principal introdutora de espécies indesejáveis nos portos de todo o planeta e, por conseguinte, uma das maiores ameaças ao equilíbrio marinho.

A Zona Costeira Brasileira está inserida em um contexto de risco, principalmente no que diz respeito às atividades portuárias, dentre elas, os procedimentos que envolvem a água de lastro nessa região geográfica. Os problemas causados pela

${ }^{38}$ CAPRA, Fritjof. Conexões ocultas - ciência para uma vida sustentável. São Paulo: Cultrix, 2002.

${ }^{39}$ CAPRA, Fritjof. A teia da vida. São Paulo: Cultrix, 2002.

40 PAMPLONA, Daneile. O Supremo tribunal federal e as decisões de questões políticas. Curitiba: Juruá, 2011, p. 197.

${ }^{41}$ DWORKIN, Ronald. Los derechos en serio. Barcelona: Ariel, 1997, p303. 
DAMACENA, Fernanda Dalla Libera; SILVA, Renato Carvalho da. Bioinvasão por água de lastro: um problema de direito e uma ameaça à sustentabilidade. Revista Eletrônica Direito e Política, Programa de Pós-Graduação Stricto Sensu em Ciência Jurídica da UNIVALI, Itajaí, v.10, n.1, edição especial de 2015. Disponível em: www.univali.br/direitoepolitica - ISSN 1980-7791.

bioinvasão através da água de lastro tanto no Brasil, como em outros países, já causam prejuízos sociais, financeiros e ambientais que se multiplicam atingindo a todos, sem distinção.

Por tratar-se de um dano transfronteiriço, as medidas para minimizá-lo devem contar com a cooperação múltipla dos Estados e seus órgãos fiscalizadores. Ademais, a questão envolve os sistemas da política, economia e direito, bem como suas influências mútuas.

As técnicas conhecidas para diminuir as probabilidades de contaminação e bioinvasão através da água de lastro, envolvem o aumento do custo para as empresas de transporte marítimo, pois interferem na sua logística aumentando o tempo e, por consequência, o custo do transporte. Este fator tem grande relevância na solução deste problema já que, conforme demonstrado neste trabalho, a maior parte do transporte de mercadorias mundiais é feito pela via marítima.

Embora existam regras para o procedimento do lastro, e técnicas para diminuir a probabilidade da bioinvasão, nota-se, primeiramente, a frágil fiscalização dos agentes responsáveis por esta atividade. Ademais, a poluição por água de lastro não tem regulamentação específica sancionatória em nosso ordenamento jurídico, embora seja plenamente possível sua prevenção pela utilização de normas internacionais.

Em complemento ao problema da fiscalização administrativa, observou-se que são poucas as decisões judiciais definitivas sobre a matéria, mas muitas as ações em tramitação. As ações civis públicas referidas neste trabalho demonstram a dificuldade que engendram o problema. A principal delas diz com a incerteza científica. A maior característica do direito, qual seja, decidir, vê-se fortemente confrontada diante das incertezas apresentadas pela ciência. Nesse contexto, o direito deve equilibrar-se entre paradigma da segurança jurídica e da incerteza científica que, hoje, trabalha no campo das probabilidades.

Enquanto a resposta da ciência para a erradicação do problema da bioinvasão não chega, há que investir em toda forma de mitigação. Por exemplo, as 
DAMACENA, Fernanda Dalla Libera; SILVA, Renato Carvalho da. Bioinvasão por água de lastro: um problema de direito e uma ameaça à sustentabilidade. Revista Eletrônica Direito e Política, Programa de Pós-Graduação Stricto Sensu em Ciência Jurídica da UNIVALI, Itajaí, v.10, n.1, edição especial de 2015. Disponível em: www.univali.br/direitoepolitica - ISSN 1980-7791.

embarcações estão orientadas a fazer a troca da água contida em seus tanques de lastro a uma distância de 200 milhas náuticas até a linha da costa do porto receptivo. Atualmente, a troca de lastro em alto-mar é considerada como o mais efetivo método preventivo, disponível no momento, para minimizar a transferência de espécies indesejáveis. Medidas como essa podem representar muito no estágio atual da bioinvasão. A desconsideração dessa orientação é grave, deve ser responsabilizada pela atividade fiscalizatória e, conforme o caso, pela atuação firme e precavida do poder judiciário. O direito precisa mudar comportamentos para garantir o direito ao futuro ou à sustentabilidade. ${ }^{42}$

\section{REFERÊNCIAS DAS FONTES CITADAS}

AMBIENTEBRASIL. Justiça dá prazo para Ibama e governo gaúcho iniciarem combate a mexilhão invasor. Ambiente Brasil, São Paulo, 2006. Disponível em: <http://www.ambientebrasil.com.br/noticias/index>. Acesso em: 20 nov. 2013.

BRASIL. Departamento de Portos e Costas - DPC. Normam 20, de 14 de junho de 2005. Gerenciamento da Água de Lastro de Navios. Disponível em: <https://www.dpc.mar.mil.br/Normam/N_20/Introducao.pdf>. Acesso em: 24 jul. 2013.

BRASIL. Lei no 7.661, de 16 de maio de 1989. Institui o Plano Nacional de Gerenciamento Costeiro e dá outras providências. Disponível em: <http://www.planalto.gov.br/ccivil_03/leis//7661.htm>.Acesso em: 8 jun. 2013.

BRASIL. Ministério do Meio Ambiente. Limites da zona costeira. Disponível em: <http://www.mma.gov.br/gestao-territorial/gerenciamento-costeiro/a-zonacosteira-e-seus-m\%C3\%BAltiplos-usos/caracteristicas-da-zona-costeira $>$. Acesso em: 24 mai. 2013.

BRASIL. Tribunal Regional Federal (4. Região; 9a Vara Federal de Porto Alegre). Sentença. Processo n. 2006.71.00.021446-8. Autor: Ministério Público Federal. Réus: Estado do Rio Grande do Sul e Instituto Brasileiro do Meio Ambiente e dos Recursos Naturais Renováveis - IBAMA. Juíza Federal Substituta Clarides Rahmeier. Porto Alegre, 04 de novembro de 2013. Disponível em: <http://www.trf4.gov.br/trf4/processos/visualizar_documento_gedpro.php?local $=$ jfrs $\&$ documento $=9177085 \&$ DocComposto $=\&$ Sequencia $=\&$ hash $=99 \mathrm{~d} 660229 \mathrm{e} 13$ 7d8e1a3ddc8bc724f783>. Acesso em: 15 mai. 2014.

\footnotetext{
${ }^{42}$ FREITAS, Juarez. Sustentabilidade: direito ao futuro. Belo Horizonte: Fórum, 2011, p. 152-
} 153. 
DAMACENA, Fernanda Dalla Libera; SILVA, Renato Carvalho da. Bioinvasão por água de lastro: um problema de direito e uma ameaça à sustentabilidade. Revista Eletrônica Direito e Política, Programa de Pós-Graduação Stricto Sensu em Ciência Jurídica da UNIVALI, Itajaí, v.10, n.1, edição especial de 2015. Disponível em: www.univali.br/direitoepolitica - ISSN 1980-7791.

BRASIL. Tribunal Regional Federal. (3. Região). Agravo de Instrumento n. 0018073-44.2013.4.03.0000. Agravante: Cia Energética de Sao Paulo CESP. Agravado: Ministério Publico Federal. Relatora: Desembargadora Federal Consuelo Yoshida. São Paulo, 18 de dezembro de 2013. Disponível em: <http://www.trf3.jus.br/NXT/Gateway.dIl?f=templates\&fn=default.htm\&vid=trf3 e:trf3ve>. Acesso em: 15 mai. 2014.

CAMARGO, Eldis. A integração da gestão das bacias hidrográficas com a dos sistemas estuarinos e zonas costeiras. In: GRANZIELRA, Maria L. M; GONÇALVES Alcindo (orgs). Os problemas da Zona costeira no Brasil e no mundo.Santos: Leopoldianum, 2012.

CANOTILHO, José Joaquim Gomes. O Princípio da sustentabilidade como Princípio estruturante do Direito Constitucional. Tékhne-Revista de Estudos Politécnicos, n. 13, p. 07-18, 2010.

CARVALHO, Delton Winter de. A zona costeira brasileira e o gerenciamento dos danos ambientais futuros. Direito e ambiente. Portugal: Lusíada, 2011. p. 4. Disponível em: <http://www.icjp.pt/sites/default/files/media/895-1638.pdf>. Acesso em: 24 mai. 2013.

CARVALHO, Délton Winter de. DAMACENA, Fernanda Dalla Libera. Direito dos desastres. Porto Alegre: Livraria do advogado, 2013.

CAPRA, Fritjof. Conexões ocultas - ciência para uma vida sustentável. São Paulo: Cultrix, 2002.

A teia da vida. São Paulo: Cultrix, 2002.

COLLYER, Wesley. Água de lastro, bioinvasão e resposta internacional. Revista Jurídica, Brasília, DF, v. 9, n. 84, abr./maio, 2007. Disponível em: <http://www.planalto.gov.br/ccivil_03/revista/Rev_84/artigos/WesleyCollyer_rev 84.htm>. Acesso em: 24 mai. 2013.

DWORKIN, Ronald. Los derechos en serio. Barcelona: Ariel, 1997.

FERREIRA, Carlos Eduardo L. GONÇALVES, José Eduardo A. COUTINHO, Ricardo. Cascos de Navios e Plataformas como vetores na Introdução de Espécies Exóticas. In: SILVA, Julieta Salles Vianna da. SOUZA, Rosa Cristina Correa Luz de (Org.). Água de lastro e bioinvasão. Rio de Janeiro: Interciência, 2004.

FREITAS, Mariana Almeida Passos de. Zona costeira e meio ambiente. Curitiba: Juruá, 2011.

FREITAS, Juarez. Sustentabilidade: direito ao futuro. Belo Horizonte: Fórum, 2011.

GUIMARÃES, Cristina. Mundo decide até 2004 como evitar desastres ambientais trazidos pelos navios. Radio Brasil, Brasília, DF, 2000. Disponível em: 
DAMACENA, Fernanda Dalla Libera; SILVA, Renato Carvalho da. Bioinvasão por água de lastro: um problema de direito e uma ameaça à sustentabilidade. Revista Eletrônica Direito e Política, Programa de Pós-Graduação Stricto Sensu em Ciência Jurídica da UNIVALI, Itajaí, v.10, n.1, edição especial de 2015. Disponível em: www.univali.br/direitoepolitica - ISSN 1980-7791.

<http://www.radiobras.gov.br/especiais/meioambiente_navios/poluicaonavios_c apa.htm>. Acesso em: 30 nov. 2013.

INSTITUTO BRASILEIRO DE GEOGRAFIA E ESTATÍSTICA (IBGE). Espécies exóticas marinhas - grupos biológicos por unidade da federação (UF). Rio de Janeiro, $2013 . \quad$ Disponível em: <http://saladeimprensa.ibge.gov.br/noticias?view = noticia\&id=1\&idnoticia =2036 >. Acesso em: 10 jul. 2013.

JURAS, Ilidia da A. G. Martins. Problemas causados pela água de lastro. Brasília, DF: Câmara dos Deputados, 2003.

LOPES, Rubens M. O departamento de oceanografia biológica do Instituto Oceanográfico da Universidade de São Paulo. In: Palestra no XVII Simpósio de Biologia Marinha. São Paulo: USP, 2006. Disponível em: <http://www.usp.br/cbm/novo_site/simposio/simp_xvii/resumos/simp_palestras _lopes.html>. Acesso em: 11 dez. 2013.

MACHADO, Paulo Affonso Leme. Direito ambiental brasileiro. 19a ed. São Paulo: Malheiros, 2011. p. 1071.

OCTAVIANO, Eliane Maria. Curso de direito marítimo: teoria geral. v.1. 4. Ed. Barueri: Manole, 2013.

PAMPLONA, Daneile. O Supremo tribunal federal e as decisões de questões políticas. Curitiba: Juruá, 201.

POPPER, Karl R. A lógica da pesquisa científica. Tradução de Leonidas Hegenberg e Octanny da Motta. São Paulo: Cultrix, 1972.

PARDO, José Esteve. EI desconcierto del Leviatã: política y derecho ante las incertidumbres de la ciência. Buenos Aires: marcial Pons, 2009.

SECRETARIA DO MEIO AMBIENTE - SEMMAN. Relatório expedição mexilhão dourado. São Leopoldo, 2005.2 Disponível em: <http://www.saoleopoldo.rs.gov.br/download_anexo/Controle\%20mexilhao\%20 dourado.pdf>. Acesso em: 11 dez. 2013.

SILVA, Ariel Scheffer da. Água de lastro e as espécies exóticas. Ambiente Brasil, São Paulo, 2007. Disponível em: <http://www.ambientebrasil.com.br/composer.php3?base=./agua/salgada/index .html\&conteudo=./agua/salgada/artigos/aguadelastro.html>. Acesso em: 20 jan. 2014.

SILVA, Geraldo Eulália do Nascimento. Direito ambiental internacional. Rio de Janeiro: Thex, 1995.

STRESSER, Rafaela de Carvalho. Água de lastro: desastre ambiental. In: CONGRESSO INTERNACIONAL DE DIREITO AMBIENTAL, v.3, 2007, São Paulo. 
DAMACENA, Fernanda Dalla Libera; SILVA, Renato Carvalho da. Bioinvasão por água de lastro: um problema de direito e uma ameaça à sustentabilidade. Revista Eletrônica Direito e Política, Programa de Pós-Graduação Stricto Sensu em Ciência Jurídica da UNIVALI, Itajaí, v.10, n.1, edição especial de 2015. Disponível em: www.univali.br/direitoepolitica - ISSN 1980-7791.

Meio ambiente e acesso à justiça: flora, reserva legal e app. São Paulo: Imprensa Oficial do Estado de São Paulo, 2007.

VERMULM JUNIOR, Harry. GIAMAS, Maria Teresa Duarte. Ocorrência do mexilhão dourado Limnoperna fortunei (Dunker, 1857) (Mollusca; Bivalvia; Mytilidae), no trato digestivo do "Armal" Pterodoras granulosus (Valenciennes, 1821) (Siluriformes; Doradidae), do rio Paraná, São Paulo, Brasil. Boletim Instituto de Pesca: São Paulo, v. 34, n. 1, p.175 - 179, 2008. Disponível em: <ftp://ftp.sp.gov.br/ftppesca/34_1_175-179.pdf>. Acesso em: 24 mai. 2013.

ZANELLA, Tiago Vinicius. Água de Lastro: Um problema ambiental global. Curitiba: Juruá, 2010.

Submetido em: Setembro/2014

Aprovado em: Outubro/2014 